\title{
Immune-regulating effects of exercise on cigarette smoke-induced inflammation
}

\author{
Ashkan Madani' \\ Katharina Alack ${ }^{2}$ \\ Manuel Jonas Richter ${ }^{3,4}$ \\ Karsten Krüger' \\ 'Department of Exercise and Health, \\ Institute of Sports Science, Leibniz \\ University Hannover, Germany; \\ ${ }^{2}$ Department of Sports Medicine, \\ University of Giessen, Germany; \\ ${ }^{3}$ Department of Internal Medicine, \\ Justus Liebig University Giessen, \\ Universities of Giessen and Marburg \\ Lung Center (UGMLC), Germany; \\ ${ }^{4}$ German Center for Lung Research \\ (DZL), Giessen, Germany
}

This article was published in the following Dove Press journal: Journal of Inflammation Research

\begin{abstract}
Long-term cigarette smoking (LTCS) represents an important risk factor for cardiac infarction and stroke and the central risk factor for the development of a bronchial carcinoma, smoking-associated interstitial lung fibrosis, and chronic obstructive pulmonary disease. The pathophysiologic development of these diseases is suggested to be promoted by chronic and progressive inflammation. Cigarette smoking induces repetitive inflammatory insults followed by a chronic and progressive activation of the immune system. In the pulmonary system of cigarette smokers, oxidative stress, cellular damage, and a chronic activation of pattern recognition receptors are described which are followed by the translocation of the NF-kB, the release of pro-inflammatory cytokines, chemokines, matrix metalloproteases, and damage-associated molecular patterns. In parallel, smoke pollutants cross directly through the alveolus-capillary interface and spread through the systemic bloodstream targeting different organs. Consequently, LTCS induces a systemic low-grade inflammation and increased oxidative stress in the vascular system. In blood, these processes promote an increased coagulation and endothelial dysfunction. In muscle tissue, inflammatory processes activate catabolic signaling pathways followed by muscle wasting and sarcopenia. In brain, several characteristics of neuroinflammation were described. Regular exercise training has been shown to be an effective nonpharmacological treatment strategy in smoke-induced pulmonary diseases. It is well established that exercise training exerts immune-regulating effects by activating anti-inflammatory signaling pathways. In this regard, the release of myokines from contracting skeletal muscle, the elevations of cortisol and adrenalin, the reduced expression of Toll-like receptors, and the increased mobilization of immune-regulating leukocyte subtypes might be of vital importance. Exercise training also increases the local and systemic antioxidative capacity and several compensatory mechanisms in tissues such as an increased anabolic signaling in muscle or an increased compliance of the vascular system. Accordingly, regular exercise training seems to protect long-term smokers against some important negative local and systemic consequences of smoking. Data suggest that it seems to be important to start exercise training as early as possible.
\end{abstract}

Keywords: physical activity, pulmonary system, muscle wasting, lymphocytes, tobacco, airway epithelial cells

\section{Introduction}

Tobacco use is the most significant preventable cause of morbidity and mortality, with $\sim 5$ million deaths caused by direct tobacco use and $>600,000$ deaths due to secondhand smoke worldwide every year. Cigarette smoking (CS) is the most common form of tobacco consumption in most countries. ${ }^{1}$ Due to the well-known detrimental effects of long-term cigarette smoking (LTCS) on health, many countries have implemented
Correspondence: Karsten Krüger Department Exercise and Health, Leibniz University Hannover, Am Moritzwinkel 6, 30167 Hannover, Germany Email karsten.krueger@sportwiss.unihannover.de 
intensified tobacco control efforts which resulted in a reduced prevalence of daily smoking since 1980 . However, in many countries, the number of smokers is actually increasing, and there are preliminary indications that global prevalence among men will increase further in the next years. ${ }^{1,2}$

LTCS represents an important risk factor for cardiac infarction and stroke and the central risk factor for the development of a bronchial carcinoma, smoking-associated interstitial lung fibrosis, and chronic obstructive pulmonary disease (COPD). About 20\% of smokers develop a COPD which is actually ranking as the fifth most common cause of mortality worldwide. ${ }^{2}$ Also, smoking cessation does not reverse the progression of COPD in patients, indicating that smoking is an important cause, but not the only driver of disease progression in COPD patients. COPD is characterized not only by the destruction of lung tissue but also by a systemic inflammation. It is suggested that a sustained systemic inflammation develops during LTCS, resulting in COPD and its comorbidities such as muscle wasting, vascular diseases, heart diseases, and stroke. ${ }^{3,4}$ The purpose of this review was to summarize the current knowledge about cigarette smoke-induced inflammation. Studies about the immunological effects of acute smoking, LTCS, secondhand CS, and COPD patients were included. In order to describe the molecular mechanisms of smoke-induced inflammation, in vitro studies and animal studies of smoke exposure were also included. The purpose of the second part of the review was to describe the current knowledge of the immuneregulating systemic and local potentials of regular exercise training after smoke-induced inflammation.

\section{Methods}

We searched various electronic databases such as PubMed, Web of Sciences, and Cochrane Library for English language articles without any date restriction. Our review focused on the effects of CS-induced inflammation on different organs (such as brain, lung, heart, muscle, etc) as well as on immune-regulating effects of exercise which may counteract CS-induced inflammation. Search terms on PubMed (abstract and/or title) as shown in Table 1 were used. After careful review of titles and abstracts, it was decided whether the full-text will further be analyzed and consequently considered in this review.

\section{From CS to inflammation}

The mechanisms of initiation and persistence of cigarette smoke (CS)-induced inflammation are not completely understood. CS comprises about 4,000 chemicals, including several carcinogens. Toxicologic studies have revealed a multitude of immunomodulatory chemicals and gas. ${ }^{5}$ Consequently, LTCS results in repetitive inflammatory insults leading to a chronic and progressive activation of the immune system accompanied by an abnormal inflammatory response of the airways to various noxious gases and particles. ${ }^{6,7}$ On the one hand, smoke pollutants cross through the alveolus-capillary interface and spread directly through the systemic bloodstream targeting different organs. ${ }^{7}$ At this point, they might be recognized by receptors of the innate immune system which initiate inflammatory signaling cascades via NF- $\kappa B$ activation. ${ }^{5}$ On the other hand, inflammatory processes are suggested to originate in the pulmonary system. Here, toxic substances disturb the barrier function of the respiratory epithelium and impact both innate and adaptive host defense mechanisms. This primarily local inflammatory processes spillover into the circulation leading to inflammatory and degenerative processes in other organs and tissues. Thus, inflammation is suggested to be the main driver of the central comorbidities. $^{7,8}$

Table I Search terms on PubMed

\begin{tabular}{lll}
\hline Focus CS-induced inflammation & & \\
\hline Category A & (AND/OR) Category B & (AND/OR) Category C \\
\hline $\begin{array}{l}\text { Cigarette, cigarette smoke, cigarette smoking, } \\
\text { tobacco, tobacco smoke, tobacco smoking }\end{array}$ & $\begin{array}{l}\text { Defense, immune, immune cell, immune } \\
\text { response immune system, inflammation }\end{array}$ & $\begin{array}{l}\text { Alveolar, brain, cardiac, cardiac muscle, } \\
\text { endothelium, endothelial, heart, HMEC, HUVEC, } \\
\text { lung, muscle, myocardium, skeletal muscle }\end{array}$ \\
\hline Focus immune-regulating effects of exercise & & \\
\hline Category A & (AND) Category B & (AND/OR) Category C \\
\hline $\begin{array}{l}\text { Aerobic, balance training, bicycling, endurance } \\
\text { training, exercise, non-aerobic, physical activity, } \\
\text { physical fitness, run, swim, walk II, resistance } \\
\text { training, strength training }\end{array}$ & $\begin{array}{l}\text { Defense, immune, immune cell, immune } \\
\text { response immune system, inflammation }\end{array}$ & $\begin{array}{l}\text { Cigarette, cigarette smoke, cigarette smoking, } \\
\text { tobacco, tobacco smoke, tobacco smoking }\end{array}$ \\
\hline
\end{tabular}

Abbreviations: HMEC, human microvascular endothelial cell; HUVEC, human umbilical vein endothelial cell. 


\section{Effects of CS on inflammatory processes in respiratory tract and lungs}

CS comprises various components that damage the pulmonary epithelium. LTCS has been shown to injure the cell membranes and alter the mucosal permeability. ${ }^{9}$ Cellular damage is followed by a compromised immune status, allowing opportunistic pathogens to cause infections that might amplify the inflammatory processes. Furthermore, components of the innate and adaptive immune system are chronically activated. Analysis of bronchoalveolar lavage fluid and breath condensate provides evidence that even acute exposure to cigarette smoke results in oxidative stress and tissue damage as suggested by increased products of lipid peroxidation and degradation products of extracellular matrix proteins. ${ }^{5}$ In bronchoalveolar lavage (BAL) of long-term smokers, an increase of interleukin (IL)-1 $\beta$, IL-6, IL-8, monocyte chemoattractant protein-1 (MCP-1), macrophage inflammatory protein (MIP)- $1 \alpha$, regulated on activation, normal T-cell expressed and secreted (RANTES), tumor necrosis factor (TNF)- $\alpha$, IL-12 (p40), and IL-17 was found. ${ }^{10,11}$ Recent data suggest that airway epithelial cells (AECs) which represent a first line of defense against inhaled toxicants have altered inflammatory signaling in response to CS exposure. These cells were shown to upregulate cytokine expression and expression of matrix metalloproteases (MMPs) via extracellular signal-regulated kinase (ERK) signaling and increased p38 activation. Furthermore, AECs show characteristics of cellular damage and cell death consequently leading to the release of damage-associated molecular patterns (DAMPs) into the extracellular space. DAMPs target pattern recognition receptors such as Toll-like receptor (TLR). TLRs are found on both immune and epithelial cells throughout the pulmonary system. TLRs recognize patterns of bacteria, fungi, and viruses, and the levels of TLR4 are elevated in cigarette smokers with COPD. After TLR activation, the NF-kB pathway is induced followed by the secretion of a variety of pro-inflammatory cytokines. ${ }^{12}$ In particular, MMP-9 and -12, surfactant protein D, and IL-1, IL-6, IL-8, and IL-17 have been found in higher quantities in the lungs of long-term smokers with the ongoing inflammation..$^{10}$ In parallel, immune cells, macrophages, neutrophils, dendritic cells, and lymphocytes migrate into the pulmonary system. ${ }^{11-13}$ Alveolar macrophages might play a key role in the pathogenesis of inflammation in lungs. These cells produce increased levels of MMPs, such as MMP-1, MMP-2, MMP-9, MMP-12, and MMP-14, after smoke exposure (Figure 1). ${ }^{10}$

\section{Specific role of lymphocytes}

Currently, it is discussed that lymphocytes might play a crucial role in inflammatory pathogenesis. Specifically, $\mathrm{CD} 8^{+} \mathrm{T}$ lymphocytes have been shown to be dramatically increased in the lungs of heavy smokers accompanied by a shift toward a type 1 profile. This immune cell subtype produces large amounts of interferon- $\gamma$ and releases perforins and granzyme. Also B lymphocytes are activated, and it is suggested that their antigen-specific responses could turn against self-epitopes, partly because of impaired tolerance. In parallel, smoke exposure led to an accumulation of forkhead-box-protein (FOX)P31 T-regulatory cells (Tregs) in lungs of mice which might participate in controlling inflammatory processes ${ }^{14}$ Accordingly, LTCS seems to alter the pulmonary immune equilibrium which turns into a chronic activated, immunosuppressed condition. ${ }^{15}$

\section{Effects of LTCS on systemic inflammation}

Every smoked cigarette seems to elicit a slight increase of oxidative stress and inflammation in blood indicated by an increase of thiobarbituric acid-reactive substances, neutrophil elastase, leukotrienes, and neutrophils after acute CS in humans. ${ }^{5}$ Chronically, most studies agree that LCTS induces an increase in the numbers of circulating neutrophils, macrophages, and lymphocytes. These cells show several inflammatory characteristics such as expression of activation markers and adhesion molecules which might mediate the migration into the bronchoalveolar system or other tissues. ${ }^{8,16}$ On the molecular levels, LTCS induces a systemic low-grade inflammation characterized by chronically elevated levels of various markers for inflammation, tissue deterioration, and coagulation, such as $\mathrm{C}$-reactive protein (CRP), TNF- $\alpha$, von Willebrand factor (vWF), tissue inhibitor of metalloproteinases-1, factor VII, and fibrinogen. Blood is suggested to be a transit way for transfer and spreading these molecules which target other organs and tissues. ${ }^{17,18}$

\section{Effects of CS on the vascular endothelium}

The particulate phase of CS consists of lipophilic components, which can pass the lipid bilayer of respiratory membranes; therefore, the damage is not limited to the lung tissue as it can also affect the vascular system. ${ }^{19}$ The integrity of endothelial cells (ECs) is essential, since it preserves vascular homeostasis, allows continuous adjustment of vascular tone and maintenance of blood fluidity, and regulates leukocyte traffic. ${ }^{20}$ Components of CS are toxic for ECs, and LTCS can lead to dysfunction of ECs, ${ }^{21}$ an early hallmark of atherosclerosis. ${ }^{22}$ Endothelial dysfunction is characterized by an imbalance of vasoconstrictors and vasodilators, aberrant interaction between endothelial and immune cells, and higher expression of adhesion molecules. ${ }^{23}$ Dysfunctional ECs express lower levels of prostacyclin, thrombomodulin, 


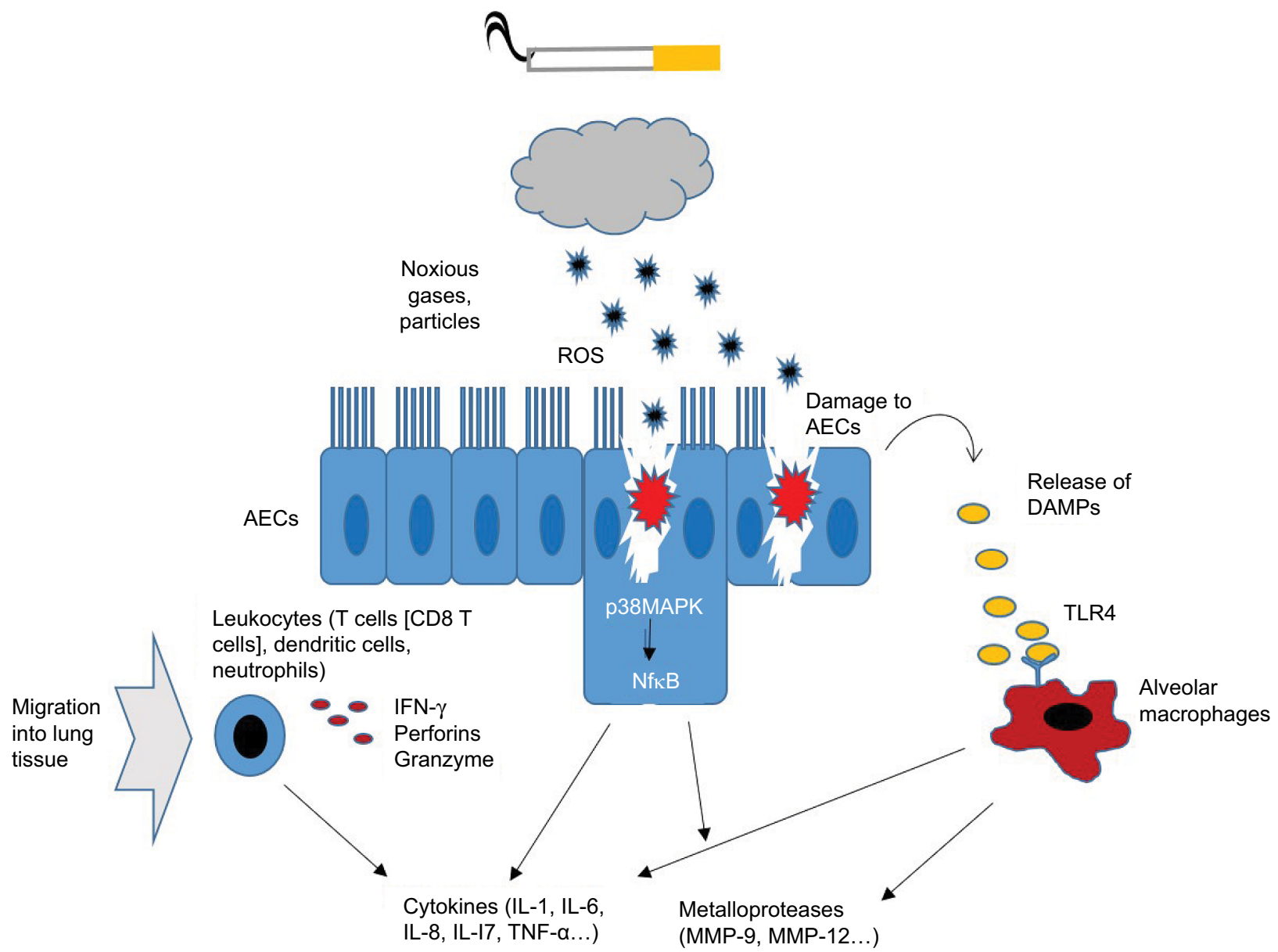

Figure I Illustration about cigarette-induced induction of oxidative stress and inflammation in AECs.

Abbreviations: AEC, airway epithelial cell; TLR4, Toll-like receptor-4; DAMP, damage-associated molecular pattern; MMP, matrix metalloprotease; ROS, reactive oxygen species; IL, interleukin; TNF, tumor necrosis factor; IFN, interferon.

tissue plasminogen activator (tPA), and NO while expression levels of endothelin-1, angiotensin II, plasminogen activator inhibitor-1 (PAI-1), and vWF are increased. ${ }^{20}$ Therefore, CS favors inflammatory processes in ECs and is a huge risk factor for the development of atherosclerosis and cardiovascular diseases (CVDs). ${ }^{22}$ In vitro studies in ECs demonstrate that CS induces cell injury in a dose- and time-dependent manner ${ }^{24}$ which can lead to apoptosis, ${ }^{25}$ autophagic cell death, ${ }^{26}$ and necrosis. ${ }^{27}$ Different mechanisms are responsible for the induction of apoptosis in ECs induced by CS. One study showed that aqueous filtrates of CS lead to mitochondrial membrane depolarization, representing an early step in the apoptotic pathway. ${ }^{22}$ The negative influence of CS on apoptotic-related genes has also been reported. For example, $\mathrm{CS}$ decreases $\mathrm{p} 53$ and $\mathrm{Bcl}-2$ expression, ${ }^{28}$ disrupts the vascular endothelial growth factor (VEGF), and fluid shear stress-mediated VEGFR2/phosphoinositide 3-kinase (PI3K) signaling pathway ${ }^{29}$ and reduces the cytochrome-c oxidase II expression through aberrant DNA methylation. ${ }^{25}$
Vascular damage through excessive apoptosis was also shown to be initiated by a $\mathrm{p} 53$-independent caspase- 3 activating pathway. ${ }^{30} \mathrm{EC}$ injury may also be mediated through protein carbonylation which is caused by reactive species in CS. ${ }^{31}$ Recruitment of leukocytes to the inflammation site happens by cytokine signaling, MMP-1 and MMP-9 upregulation, and through cell adhesion of immune cells to ECs. ${ }^{32}$

\section{Potential mechanisms of atherogenesis}

The underlying mechanism of atherogenesis of ECs induced by CS is not fully understood yet. ${ }^{33}$ So far, CS-induced inflammation-related responses have been described in experimental studies in vitro. CS led to phosphorylation of various mitogen-activated protein kinases (MAPK), like p38, ${ }^{34}$ c-Jun N-terminal kinase (JNK), and ERK. ${ }^{34,35}$ The expression levels of osteopontin, ${ }^{35}$ E-selectin, intercellular cell adhesion molecule-1 (ICAM-1) ${ }^{36}$ and IL- $8{ }^{37}$ were also induced by CS. Furthermore, CS induced nicotinamide adenine dinucleotide phosphate $(\mathrm{NAD}(\mathrm{P}) \mathrm{H})$-oxidase-derived 
$\mathrm{H}_{2} \mathrm{O}_{2}$ generation, ${ }^{38}$ upregulated fractalkine (CX3CL1), increased IL-13R $\alpha 2$ through the activation of protein kinase A-cAMP response element-binding protein (PKA-CREB) pathway, ${ }^{39}$ increased cyclooxygenase-2 (COX-2) expression through nuclear $\beta$-catenin accumulation due to the activation of epidermal growth factor receptor (EGFR)/Akt/glycogen synthase kinase- $3 \beta$ pathways. ${ }^{40}$ One cell culture study demonstrated that ECs treated with CS for 72 hours expressed only minor differences in various cytokines on mRNA level. ${ }^{41}$ CS promotes endothelial dysfunction as well by impairing endothelium-dependent relaxation, presumably through suppression of NO production ${ }^{42}$ and CS-low-density lipoprotein (CS-LDL). ${ }^{43}$ Cell culture studies proved that exposure of ECs to CS impaired the VEGF-induced EC migration ${ }^{44,45}$ and tube formation, explaining the negative effect of CS on vessel growth and endothelial function. ${ }^{45}$

\section{Effect of smoking on the cardiac tissue}

Persistent inflammation is an important factor in the development of CVD. ${ }^{46}$ Since CS promotes inflammation ${ }^{47}$ and injures the cardiovascular system chronically, it is not surprising that the risk for CVD is twice as high in smokers than in nonsmokers. ${ }^{48}$ Toxic effects of CS on the myocardium have been proved experimentally as well as clinically, ${ }^{15}$ but whether smoking is a direct or indirect cause of CVD still needs to be proved. ${ }^{49}$ It is somehow remarkable that even secondhand smoke has the ability to increase the risk for CVD to as high as $30 \%{ }^{48,50-54}$ Secondhand smoking combined with an unhealthy lifestyle was shown to reduce the ability of the heart adapt sensitively to sidestream smoke in a murine model..$^{48}$ Furthermore, in nonsmoking humans, secondhand smoking increased WBC count immediately as well as CRP levels 18 $\mathrm{h}$ after exposure. Both of these are markers for inflammation and have been linked to a higher incidence of CVD. ${ }^{50}$

The situation for smokers is worse. Active smoking increases cardiac afterload, promotes a pro-thrombotic status, reduces fibrinolysis, changes the profile of circulating lipids, ${ }^{48}$ promotes neutrophil infiltration in the myocardium, ${ }^{55}$ alters T-cell function, ${ }^{56}$ and causes DNA adducts in the myocardium. ${ }^{57} \mathrm{CS}$ leads to the production of reactive oxygen species (ROS) which initiate ROS-sensitive signal transduction pathways, such as MAPKs, and various transcription factors, including NF-kB ${ }^{15}$ resulting in an aberrant cytokine profile. ${ }^{58-60}$ Gene analysis of the hearts of mice revealed an upregulation of the xenobiotic-metabolizing enzyme cytochrome P-450 1A1 and a downregulation of PAI-1, representing a key gene involved in fibrinolysis. ${ }^{61}$ Taken together, all mentioned factors are suggested to increase the risk for several diseases of the cardiovascular system also in human smokers. ${ }^{62}$

\section{Effects of LTCS on muscle tissue}

Human smokers tend to have a lower BMI while central or abdominal obesity seems to be increased. Thus, the weight loss associated with tobacco smoking may be due to loss of lean mass rather than fat. ${ }^{63}$ It is suggested that inflammation and oxidation of proteins are two main contributors to the development of skeletal muscle loss and dysfunction observed in LTCS and COPD patients. ${ }^{63}$ Structurally, LTCS leads to a reduced percentage of type I fiber, a lower muscle fiber cross-sectional area, an increased glycolytic enzymatic activity, and decreased muscle oxidative activity. ${ }^{8,63,64}$ Mice chronically exposed to cigarette smoke tend to a reduced muscle capillary to fiber ratio along with decreased VEGF, lowered endothelial and neuronal nitrite oxide synthase activities in muscle vessels, and increased inflammatory activity indicated by an increased mRNA expression of TNF- $\alpha$ and IL-1 $\beta .^{8,64,65}$ The role of numerous cell signaling pathways in the development of skeletal muscle atrophy, a key element of muscle dysfunction in long-term cigarette smokers and COPD patients, has been investigated. ${ }^{65}$ In general, atrophy occurs when protein degradation exceeds protein synthesis. With regard to protein degradation, the ubiquitin proteasome system (UPS) seems to have an important role during LTCS. In smoke-exposed mice, an increased ubiquitination of target proteins was demonstrated, which was indicated by the increased activities of the E3 ubiquitin ligases atrogin-1 and muscle RING finger protein-1 (MuRF1). ${ }^{66}$ In parallel, key factors that induce protein synthesis such as insulin-like growth factor 1 (IGF-1), are reduced followed by a lower activation of anabolic signaling pathways such as protein kinase B (Akt) and rapamycin (mTOR) pathways. All the mentioned pathways interact with inflammatory signaling molecules such as TNF- $\alpha$ turning protein balance toward an enhanced degradation leading to muscle wasting. ${ }^{63,66}$

\section{Effects of LTCS on brain inflammation}

Atherosclerosis and vascular brain lesions share similar pathological features such as oxidative stress and increased inflammation ${ }^{67}$ Oxidative stress, for example, plays a decisive role in the pathogenesis of ischemic brain injury. ${ }^{68}$ It is not surprising that direct and secondhand CS are associated with various cerebrovascular-related diseases,${ }^{32}$ in particular, smoking is a risk factor for stroke. ${ }^{69}$

Likewise to the effects of CS on endothelial cells,${ }^{70}$ higher expression of VEGF, ICAM-1, IL-8, and nuclear factor 
(erythroid-derived 2)-like 2 was also observed in cultured brain ECs. ${ }^{71}$ Furthermore, it was shown that CS extracts induced heme oxygenase-1 (HO-1) expression mediated by phosphatidylcholine phospholipase $\mathrm{C}$ /protein kinase $\mathrm{C} \delta$ / NADPH oxidase-dependent platelet-derived growth factor receptor (PDGFR)/PI3K/Akt pathway. ${ }^{19}$ Higher HO-1 expression was shown to exacerbate early brain injury during intracerebral hemorrhagic stroke. ${ }^{72}$ Endothelin-1 levels decreased in rat brains exposed to CS, implying that endothelin-1 may contribute to the hemodynamic response to chronic $\mathrm{CS}^{73}$

\section{Effects on brain ECs}

Moreover, animal experiments proved that CS negatively affected endothelial tight junctions ${ }^{71}$ and downregulated the activity of $\mathrm{Na}-\mathrm{K}-2 \mathrm{Cl}$ cotransporter in brain ECs. The latter could possibly contribute to an increase in extracellular $\mathrm{K}^{+}$. Therefore, CS may exacerbate ischemic cellular damage and hinder recovery from ischemic damage. In addition, accumulation of extracellular fluid $\mathrm{K}^{+}$is a risk factor for cellular edema in astrocytes and neurons and could impair neuronal conduction after stroke. ${ }^{74}$ Increased blood viscosity due to CS impairs the blood flow and risks the integrity of the brain microvasculature. ${ }^{32}$ On top of everything, CS negatively affects the viability of the blood-brain barrier (BBB). Taken together, CS and hemodynamic impairments contribute synergistically to vascular inflammation and BBB damage. ${ }^{32}$ Inflammation of brain cells due to CS was also confirmed in various in vivo studies using mouse and rat models. Inflammation and cell death processes in the brain are often characterized by alterations of the neuroproteome. ${ }^{73-75}$ Mice exposed to secondhand CS, showed higher levels of ROS, induction of lipid peroxidation, activation of the transcription factors NF-kB and activator protein-1, as well as activation of MAPK, including JNK, ERK, and p38, and COX-2 in various regions of the brain. ${ }^{69}$ Furthermore, secondhand CS altered enzymatic antioxidant defenses by reducing superoxide dismutase as well as catalase and increasing glutathione S-transferase activity in rat brains. Moreover, rats exposed to secondhand CS showed increased proteolytic degradation of $\alpha$ II-spectrin through caspase-3 and dephosphorylation of phosphoprotein enriched in astrocytes-15, both indicating apoptotic cell death. ${ }^{75}$

\section{Immune-regulating effects of exercise training}

Exercise training has been shown to be an effective nonpharmacological treatment strategy in pulmonary diseases and systemic lung diseases. Furthermore, regular exercise has been shown to increase patients' strength, endurance capacity, quality-of-life scores, and symptoms of fatigue and dyspnea. ${ }^{76}$ Thus, the beneficial effects of exercise training in pulmonary rehabilitation are well established. Recent studies provided evidence that regular and moderate exercise exerts protective effects against smoke-induced lung disease due to its anti-inflammatory effects. ${ }^{64,77}$

\section{Anti-inflammatory effects of exercise}

Exercise training exerts its immune-regulating effects by activating anti-inflammatory signaling pathways. ${ }^{78,79}$ Contracting skeletal muscle produces and secretes the antiinflammatory myokine IL-6 during an acute bout of exercise, which evokes a subsequent rise in circulating levels of IL-6 followed by an ensuing increase in systemic levels of the anti-inflammatory cytokines IL-10 and IL-1RA. ${ }^{77-79}$ IL-10, which is mainly produced by Tregs, reduces tissue damage caused by inflammation and is known to diminish the adaptive immune response. ${ }^{80-82}$ Complementarily, IL-1RA is capable to limit the effects of the pro-inflammatory cytokine IL-1 $\beta$ and therefore serves as an important contributor to exercise-induced anti-inflammatory state. ${ }^{79}$ Besides, exercise-induced systemic elevations of cortisol, adrenalin, and IL- 6 inhibit the secretion of pro-inflammatory TNF- $\alpha$ by monocytes. ${ }^{78,82,83}$ Moreover, after an acute bout of strenuous prolonged exercise, a reduced expression of TLRs on monocytes can be observed, which results in subsequent inhibition of pro-inflammatory cytokines and promotes the expression of costimulatory molecules and major histocompatibility complex. ${ }^{83,84} \mathrm{CD} 14^{\text {low }} \mathrm{CD} 16^{+}$monocytes are characterized by heightened TLR-4 expression and thereby associated with pro-inflammatory properties. ${ }^{85}$ Regular exercise lowers the ratio of pro-inflammatory monocytes $\left(\mathrm{CD} 14^{\text {low }} \mathrm{CD} 16^{+}\right)$ to classical monocytes $\left(\mathrm{CD} 14{ }^{\mathrm{hi}} \mathrm{CD} 16^{-}\right) .{ }^{86}$ Chronic exercise training also increases Treg cell numbers in circulation. In detail, athletes participating in sports where aerobic capacity is a prominent factor for performance outcome seem to have increased Treg counts. ${ }^{87,88}$

\section{Specific role of exercise during obesity}

In case of obesity, exercise training stimulates anti-inflammatory signaling via a reduction in visceral fat mass, which is accompanied by a decrease in the production of several pro-inflammatory adipokines (eg, TNF- $\alpha$, leptin, retinolbinding protein) and higher levels of adiponectin, which has anti-inflammatory effects and functions as an insulin sensitizer. ${ }^{89}$ Current mouse and rat model studies indicate that acute bouts of exercise and exercise training stimulate 
phenotypic switching from M1-type macrophages producing TNF, IL-6, and nitric oxide toward M2-type macrophages, which release arginase and anti-inflammatory cytokines. ${ }^{90,91}$ In addition, after exercise training, a reduced tissue expression of ICAM-1, which is involved in the adhesion of inflammatory cells to endothelium and conveys interactions of $\mathrm{T}$ cells with target cells, and an inhibition of pro-inflammatory M1-type macrophage migration in adipose tissue occur. ${ }^{91}$

\section{Effects of exercise on pulmonary system after LTCS}

Experimental animal studies demonstrated that aerobic exercise after $\mathrm{CS}$ exposure or asthma induction reduces lung inflammation ${ }^{92}$ and remodeling. ${ }^{93,94}$

In particular, exercise was shown to increase Th1 response and suppress Th2 cytokine levels in lungs of smoke-exposed mice. ${ }^{95}$ In parallel, exercise increased antioxidant defense and reduced oxidative stress markers. ${ }^{96,97}$ In CS-exposed mice, it was shown that prior exercise training significantly reduced bronchoalveolar capillary permeability, inflammatory cell infiltration, epithelial thickening, expression of proliferating cell nuclear antigen, mucin 2, cytokines, chemokines, adhesion molecules, and activation of NF- $\kappa \mathrm{B} .{ }^{98}$ These data proved an important preventive effect of exercise training for smoke-induced inflammation in lung tissue.

\section{Effects of exercise on CS-induced inflammation in blood}

Regular exercise training has been shown to lower the levels of several inflammatory, chemoattractive, and coagulative factors in the blood of smoke-exposed mice. However, some human studies and clinical trials also demonstrated that due to dyspnea, COPD patients have restricted activity levels and muscle wasting, a markedly impaired exercise capacity. ${ }^{99,100}$ Therefore, some of these patients develop a kind of exercise intolerance. In this regard, it seems to be important to start exercise programs carefully, because acute and intensive bouts of exercise are known to induce a systemic immunologic response and oxidative stress, which might force inflammation in patients. However, a pro-inflammatory effect of exercise was only shown in muscle-wasted COPD patients after acute and intensive bouts of exercise. Interestingly, this effect was partially blunted by short-term supplementary oxygen. ${ }^{100,101}$ In general, longer periods of regular exercise training show a decrease of many inflammatory cytokines such as TNF- $\alpha$, IL-2, IL-4, and CRP in COPD patients. ${ }^{102}$ Similarly, in murine models, a reduced expression of cell surface markers on circulating immune cells such as vascular adhesion molecule-1
(VCAM-1), ICAM-1, and CD62L was shown after regular treadmill running. Also several other inflammatory cytokines such as IL- $1 \alpha$, MCP-3, MIP-1 $\beta$, MIP- $1 \alpha$, and CD40L were shown to decrease in smoke-exposed mice after training. ${ }^{64} \mathrm{In}$ addition, regular endurance exercise has been shown to have favorable effects on blood coagulation by affecting fibrinolysis via decreasing vWF and factor VII. ${ }^{103}$

\section{Effects of exercise on endothelium after LTCS}

The effects of CS and exercise on the inflammation of ECs have been well established in the literature. However, to our knowledge, no study has investigated the effects of exercise toward CS-induced inflammation in blood vessels. Therefore, it can only be hypothesized how exercise possibly ameliorates CS-induced inflammation in vessel walls by its effects on inflammation in general.

Endurance exercise training promotes endotheliumdependent vasodilation ${ }^{104-108}$ which is related to a shear stress-induced and Akt-dependent phosphorylation of endothelial NOS, resulting in NO activation. ${ }^{107}$ Furthermore, regular physical activity reduces oxidative stress, ${ }^{108}$ inflammation, ${ }^{109,110}$ and promotes LDL oxidation. ${ }^{19}$ It has also been demonstrated that exercise training has a positive impact on inflammatory markers. Regular physical activity reduced the levels of circulating adhesion molecules ${ }^{111}$ like soluble intercellular adhesion molecule-1, ${ }^{12,113}$ soluble vascular adhesion molecule-1 (sVCAM-1), ${ }^{112}$ soluble P-selectin, and circulating CRP. ${ }^{109}$ Prolonged exercise sessions may increase cell adhesion molecules like P-selectin, ${ }^{113}$ E-selectin, ICAM-1, and VCAM-1 first, but the endothelium recovers rapidly afterwards. ${ }^{114}$ It is noteworthy that the potential influence of exercise training on inflammation, circulating biomarkers, and anti-oxidative capacity depends on exercise capacity. ${ }^{115-117}$ For example, heart failure patients showed reduced endothelial response toward exercise. Indeed, plasma levels of vWF and tPA remained unaffected after exercise while their values increased in healthy subjects. ${ }^{118,119}$ Therefore, endothelial dysfunction and chronic inflammation probably impair exercise capacity. ${ }^{120}$ It is therefore crucial that exercise interventions in smokers should be considered as soon as possible since its benefits may decline with the progression of possible diseases.

\section{Effects of exercise on cardiac tissue of smokers}

Smoking and physical inactivity are two avoidable risk factors for CVD. ${ }^{121}$ As endothelial dysfunction can lead to 
cardiac dysfunction, ${ }^{122,123}$ it is reasonable to assume that protective effects of exercise toward endothelium in (non-) smokers, which are mentioned above, might also be cardioprotective. The decreasing risks for CVDs through moderate exercise training are in part mediated through inducing antiinflammatory factors. ${ }^{124-127}$ Nonetheless, as it was mentioned for vessel walls, studies examining anti-inflammatory effects of exercise in CS-induced inflammation of the myocardium remain poor.

Short-time swimming exercise in CS-exposed Wistar rat could attenuate the impact of CS to the cardiovascular system compared to the control group. ${ }^{47}$ Another study with young women demonstrated that even secondhand smoking had a negative influence on exercise capacity due to reduced values of $\mathrm{VO}_{2 \max }$ and exercise duration and an increased R-to-R value. ${ }^{129}$

Exercise intensity rather than duration has a more powerful impact on physiological adaptations regarding inflammation and oxidative stress, ${ }^{128}$ like it was described for vessel walls. Even if high-risk patients with severe coronary artery disease or heart failure could benefit the most from more intensive exercise training like high-intensity interval training, its safety has not been properly established. ${ }^{130}$ For example, exercise intensity might be a critical factor for the development of exercise-induced hypertension. Increased exercise intensity could trigger more endothelial responses in the absence of inflammatory markers. Therefore, exercise intervention plans should always have to be appropriate to each condition. ${ }^{23}$

\section{Effects of exercise on muscle wasting after LTCS}

Exercise is able to reverse sarcopenia and muscle wasting in LTCS by different pathways. On the one hand, a decrease of systemic inflammation and inflammatory mediators in muscle such as TNF- $\alpha$ and IL- $1 \beta$ might indirectly reduce the activation of catabolic pathways and increase anabolic signals. ${ }^{64}$ In this regard, exercise has been shown to decrease for FoxO1 phosphorylation and reduce the expression of atrogin-1 and MuRF-1 in skeletal muscle of smoke-exposed mice. Consequently, exercise training abrogates the expression of protein catabolic E3 ligases, which are considered key factors in myofibrillar protein breakdown via the UPS. On the other hand, in particular, resistance training is also known to directly increase IGF-1 signaling followed by the activation of the Akt-mTOR-pathway. ${ }^{131,132}$ The reduction of catabolic and stimulation of anabolic signaling attenuate or reverse muscle wasting after smoke exposure. Endurance training was also shown to increase metabolic capacities of muscles by increased expression of genes involved in fatty acid transport into the mitochondrial matrix. Similarly, glucose uptake was optimized after regular exercise training. ${ }^{64}$ The differentiated effects of exercise training on muscle tissue might also depend on the mode of exercise. While endurance training more efficiently addresses type I fibers and oxidative metabolism, strength or resistance training mainly affects type II fibers, induces hypertrophy, and increases strength capabilities. However, most pulmonary rehabilitation programs include both endurance and resistance exercise to maximize gains from both modalities. Alternatively, it has been shown that combined training program which includes both resistance and endurance exercise modalities increases strength and endurance in COPD patients. ${ }^{133}$

\section{Effects of exercise on brain after LCTS}

Inflammation and vascular-induced abnormalities in the brain are two conditions associated with stroke and other neurovascular diseases, which can be protected by regular physical activity in humans. ${ }^{134}$ In humans and animals, exercise upregulates brain neurotrophin and brain-derived neurotophin factor (BDNF), which is an important factor of neuronal function, growth, and survival. BDNF increases the brain's resistance to damage and degeneration. ${ }^{135}$ The immediate response of the brain to acute exercise produces only marginal changes of inflammatory mediators. ${ }^{136}$ On the other hand, regular physical activity improves the overall immune condition in the brain. ${ }^{137}$ Murine studies proved that pro-inflammatory cytokines impair the IGF-1 signal transduction in neurons. Peripheral IGF-1 is essential in glucose metabolism and cerebrovascular function. One mechanism by which the negative effects of inflammation are counteracted by exercise is the restoration of IGF-1 signaling. ${ }^{137}$ In a study with mice, endurance and strength training decreased most of the inflammatory factors, such as IL-1 $\alpha$, IL-2, and IL-18. Interestingly, NF- $\kappa \mathrm{B}$ and COX-2 protein levels were significantly increased probably due to circulating IL-6 after training. The increased expression of COX-2 and microsomal prostaglandin E synthase, an enzyme downstream of COX2 , were independent of peripheral inflammation. ${ }^{138}$ Exercise improved oxidative stress and inflammation directly at the brain of old high-fat-fed $\mathrm{ApoE}^{-/-}$mice, reaffirming the neuroprotective effects of exercise in a model of mice with vascular brain lesions. ${ }^{138}$ On the other hand, aged mice, training above the lactate threshold showed increased levels of brain PGC-1 $\alpha$, mTOR, and phospho-mTOR protein levels, as well as citrate synthase mRNA levels. ${ }^{139} \mathrm{~A}$ similar relationship has 
been confirmed in young mice. ${ }^{140}$ In addition, for FOXO-3 translocated from the nucleus to the cytoplasm, predicting an increased and facilitated VEGF-A expression. ${ }^{141}$ Another study using rats in a traumatic brain injury model showed that aerobic exercise training enhances the endogenous anti-inflammatory response (IL-10), inhibits the infiltration of neutrophils, and attenuates BBB breakdown as well as pro-inflammatory cytokines (IL-1 $\beta, \mathrm{TNF} \alpha) .{ }^{141}$

\section{Neuroprotective effects of exercise}

Neuroprotective and anti-inflammatory effects of exercise on the brain have also been shown in humans. Moderate intensity interval training in Parkinson's disease patients attenuated inflammation by decreasing circulating SVCAM-1 and serum TNF- $\alpha$ and increasing serum BDNF levels. ${ }^{142}$

Accordingly, exercise training has the potential to be a new therapeutic approach to control acute inflammation. ${ }^{143}$ These effects remain to be proven in response to CS-induced inflammation. So far, only one study has investigated the effects of exercise training on CS-exposed brain oxidative stress. ${ }^{144}$ Mice exposed to CS showed decreased levels of BDNF and higher immobility in a forced swim test. Exercise was able to prevent oxidative damage, but surprisingly, it could neither reverse the decrease of BDNF nor it was able to prevent CS-induced depressive-like behavior. ${ }^{144}$ These results clearly show that molecular effects of exercise on CS-induced inflammation at the brain needs to be investigated in future research projects.

\section{Conclusion}

Taken together, LTCS induces local and systemic inflammatory processes which might be mediated directly by pollutant particles and a spillover of inflammatory signals to other tissues. These inflammatory processes might induce or amplify signals of tissue degradation and catabolic processes. Exercise training has been shown to prevent and even reverse inflammatory processes leading to reduced tissue degradation and catabolic processes. In parallel, exercise elicits anabolic signals leading to an increased functional capacity. Accordingly, regular exercise training seems to protect long-term smokers against some important negative local and systemic consequences of smoking. In this regard, the immune-regulating properties of exercise might have relevance (Figure 2). It has to be considered that many molecular findings from smoking or exercise effects on tissues were obtained from animal studies, and this knowledge has to be only carefully transferred to humans.

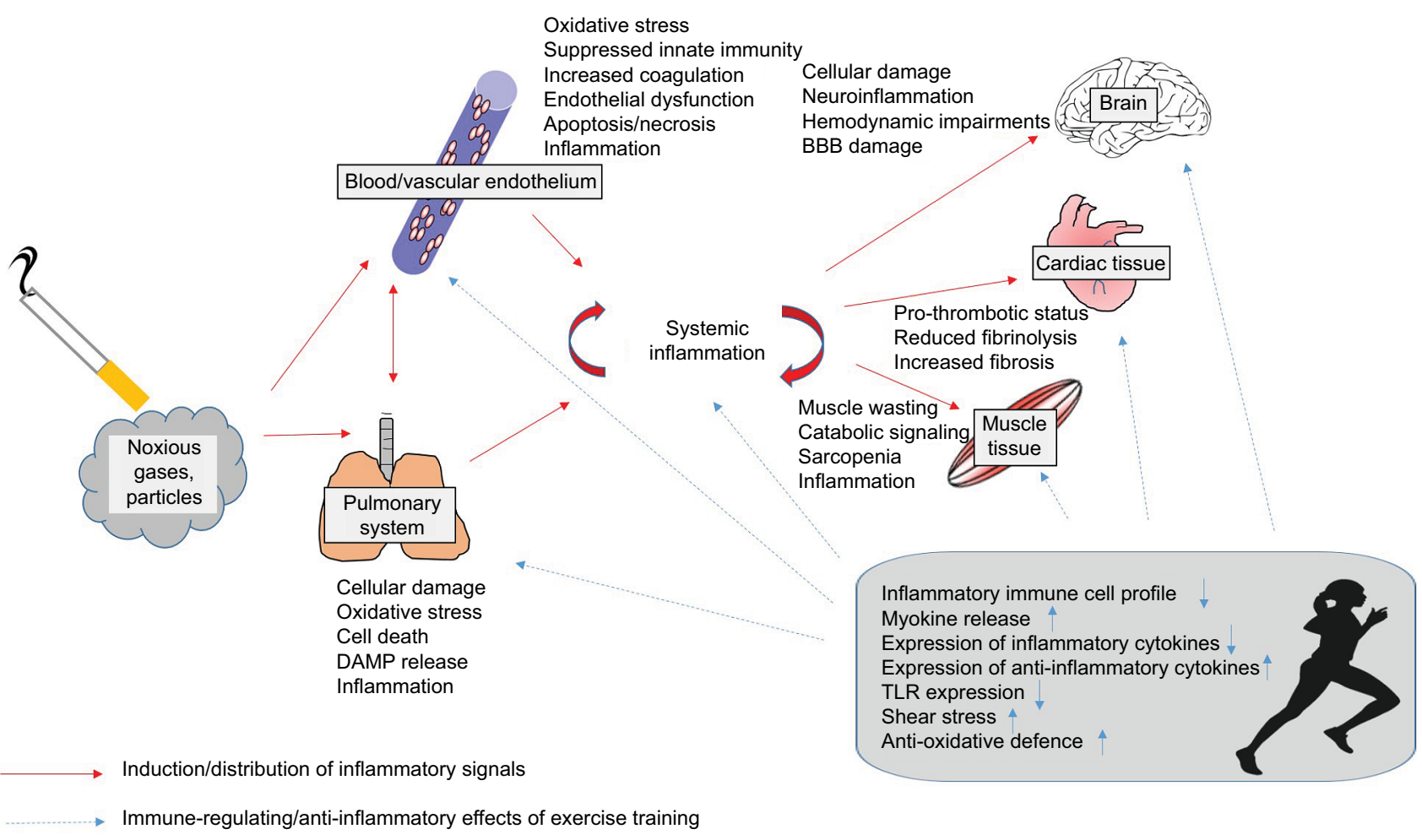

Figure 2 Overview about the distribution of inflammatory signals induced by tobacco smoking from the pulmonary system to blood, brain, cardiac tissue, and muscle and the immune-regulating effects of regular exercise training.

Abbreviations: BBB, blood-brain barrier; TLR, Toll-like receptor; DAMP, damage-associated molecular pattern. 
More studies are needed to discover the mechanisms how exercise affects inflammation in smokers. Specifically, the effects of exercise on inflammation in various organs in smokers have to be confirmed. From a clinical point of view, data suggest that it seems to be important to start exercise training as early as possible for smokers. In this regard, the progressive increase of certain inflammatory signals might be important predictors of the necessity of starting a regular exercise training program.

\section{Disclosure}

The authors report no conflicts of interest in this work.

\section{References}

1. Marie Ng, Freeman MK, Fleming TD, et al. Smoking prevalence and cigarette consumption in 187 countries, 1980-2012. JAMA. 2014;311(2): 183-192.

2. Wakefield MA, Germain D, Durkin SJ. How does increasingly plainer cigarette packaging influence adult smokers' perceptions about brand image? An experimental study. Tob Control. 2008;17(6):416-421.

3. Edwards R. The problem of tobacco smoking. BMJ. 2004;328:217-219.

4. Foschino Barbaro MP, Carpagnano GE, Spanevello A, Cagnazzo MG, Barnes PJ. Inflammation, oxidative stress and systemic effects in mild chronic obstructive pulmonary disease. Int J Immunopathol Pharmacol. 2007;20(4):753-763.

5. van der Vaart H, Postma DS, Timens W, Ten Hacken NH. Acute effects of cigarette smoke on inflammation and oxidative stress: a review. 2004;59:713-721.

6. Pauwels RA, Buist AS, Ma P, Jenkins CR, Hurd SS. Global strategy for the diagnosis, management, and prevention of chronic obstructive pulmonary disease: National Heart, Lung, and Blood Institute and World Health Organization Global Initiative for Chronic Obstructive Lung Disease (GOLD): executive summary. Respir Care. 2001;46(8):798-825.

7. Zhang J, Liu Y, Shi J, Larson DF, Watson RR. Side-stream cigarette smoke induces dose-response in systemic inflammatory cytokine production and oxidative stress. Exp Biol Med.2002;227(9):823-829.

8. Krüger K, Dischereit G, Seimetz M, Wilhelm J, Weissmann N, Mooren FC. Time course of cigarette smoke-induced changes of systemic inflammation and muscle structure. Am J Physiol Lung Cell Mol Physiol. 2015;309(2):L119-L128.

9. Rusznak C, Mills PR, Devalia JL, Sapsford RJ, Davies RK, Lozewicz, S. Effect of cigarette smoke on the permeability and IL-1b and sICAM-1 release from cultured human bronchial epithelial cells of never-smokers, smokers, and patients with chronic obstructive pulmonary disease. Am J Respir Cell Mol Biol. 2000;23:530-536.

10. Crotty Alexander LE, Shin S, Hwang JH. Inflammatory diseases of the lung induced by conventional cigarette smoke: a review. Chest. 2015;148(5):1307-1322.

11. Kou YR, Kwong K, Lee LY. Airway inflammation and hypersensitivity induced by chronic smoking. Respir Physiol Neurobiol. 2011;178:395-405.

12. Pouwels SD, Hesse L, Faiz A, et al. Susceptibility for cigarette smokeinduced DAMP release and DAMP-induced inflammation in COPD. Am J Physiol Lung Cell Mol Physiol. 2016;311(5):L881-L892.

13. Tang GJ, Wang HY, Wang JY, et al. Novel role of AMP-activated protein kinase signaling in cigarette smoke induction of IL-8 in human lung epithelial cells and lung inflammation in mice. Free Radic Biol Med. 2011;50(11):1492-1502.

14. Botelho FM, Gaschler GJ, Kianpour S, et al. Innate immune processes are sufficient for driving cigarette smoke-induced inflammation in mice. Am J Respir Cell Mol Biol. 2010;42(4):394-403.
15. Kaplan A, Abidi E, Ghali R, Booz GW, Kobeissy F, Zouein FA. Functional, cellular, and molecular remodeling of the heart under influence of oxidative cigarette tobacco smoke. Oxid Med Cell Longev. 2017;2017:3759186.

16. Majo J, Ghezzo H, Cosio MG. Lymphocyte population and apoptosis in the lungs of smokers and their relation to emphysema. Eur Respir J. 2001;17:946-953.

17. Wannamethee SG, Lowe GD, Shaper AG, Rumley A, Lennon L, Whincup PH. Associations between cigarette smoking, pipe/cigar smoking, and smoking cessation, and haemostatic and inflammatory markers for cardiovascular disease. Eur Heart J. 2005;26(17): 1765-1773.

18. Liu J, Liang Q, Frost-Pineda K, et al. Relationship between biomarkers of cigarette smoke exposure and biomarkers of inflammation, oxidative stress, and platelet activation in adult cigarette smokers. Cancer Epidemiol Biomarkers Prev. 2011;20(8):1760-1769.

19. Shih RH, Cheng SE, Hsiao LD, Kou YR, Yang CM. Cigarette smoke extract upregulates heme oxygenase-1 via PKC/NADPH oxidase/ ROS/PDGFR/PI3K/Akt pathway in mouse brain endothelial cells. J Neuroinflammation. 2011;8:104.

20. Ribeiro F, Alves AJ, Duarte JA, Oliveira J. Is exercise training an effective therapy targeting endothelial dysfunction and vascular wall inflammation? Int J Cardiol. 2010;141(3):214-221.

21. Unverdorben M, der Bij1 A, Potgieter L, Liang Q, Meyer BH, Roethig HJ. Effects of levels of cigarette smoke exposure on symptom-limited spiroergometry. Prev Cardiol. 2007;10(2):83-91.

22. Vayssier-Taussat M, Camilli T, Aron Y, et al. Effects of tobacco smoke and benzo[a]pyrene on human endothelial cell and monocyte stress responses. Am J Physiol Heart Circ Physiol. 2001;280(3):H1293-H1300.

23. Jee H, Park J, Oh JG, Lee YH, Shin KA, Kim YJ. Effect of a prolonged endurance marathon on vascular endothelial and inflammation markers in runners with exercise-induced hypertension. Am J Phys Med Rehabil. 2013;92(6):513-522.

24. Hoshino S, Yoshida M, Inoue K, et al. Cigarette smoke extract induces endothelial cell injury via JNK pathway. Biochem Biophys Res Commun. 2005;329(1):58-63.

25. Yang M, Chen P, Peng H, et al. Cigarette smoke extract induces aberrant cytochrome-c oxidase subunit II methylation and apoptosis in human umbilical vascular endothelial cells. Am J Physiol Cell Physiol. 2015;308(5):C378-C384.

26. Csordas A, Kreutmayer S, Ploner C, et al. Cigarette smoke extract induces prolonged endoplasmic reticulum stress and autophagic cell death in human umbilical vein endothelial cells. Cardiovasc Res. 2011;92(1):141-148.

27. Messner B, Frotschnig S, Steinacher-Nigisch A, et al. Apoptosis and necrosis: two different outcomes of cigarette smoke condensateinduced endothelial cell death. Cell Death Dis. 2012;3(11):e424.

28. Yang YM, Liu GT. Damaging effect of cigarette smoke extract on primary cultured human umbilical vein endothelial cells and its mechanism. Biomed Environ Sci. 2004;17(2):121-134.

29. Edirisinghe I, Rahman I. Cigarette smoke-mediated oxidative stress, shear stress, and endothelial dysfunction: role of VEGFR2. Ann NY Acad Sci. 2010;1203:66-72.

30. Wang J, Wilcken DE, Wang XL. Cigarette smoke activates caspase-3 to induce apoptosis of human umbilical venous endothelial cells. Mol Genet Metab. 2001;72(1):82-88.

31. Gornati R, Colombo G, Clerici M, et al. Protein carbonylation in human endothelial cells exposed to cigarette smoke extract. Toxicol Lett. 2013;218(2):118-128.

32. Mazzone P, Tierney W, Hossain M, Puvenna V, Janigro D, Cucullo L. Pathophysiological impact of cigarette smoke exposure on the cerebrovascular system with a focus on the blood-brain barrier: expanding the awareness of smoking toxicity in an underappreciated area. Int $J$ Environ Res Public Health. 2010;7(12):4111-4126.

33. Giunzioni I, Bonomo A, Bishop E, Castiglioni S, Corsini A, Bellosta S. Cigarette smoke condensate affects monocyte interaction with endothelium. Atherosclerosis. 2014;234(2):383-390. 
34. Low B, Liang M, Fu J. p38 mitogen-activated protein kinase mediates sidestream cigarette smoke-induced endothelial permeability. J Pharmacol Sci. 2007;104(3):225-231.

35. Bishop E, Theophilus EH, Fearon IM. In vitro and clinical studies examining the expression of osteopontin in cigarette smoke-exposed endothelial cells and cigarette smokers. BMC Cardiovasc Disord. 2012;12:75.

36. Chen HW, Lii CK, Ku HJ, Wang TS. Cigarette smoke extract induces expression of cell adhesion molecules in HUVEC via actin filament reorganization. Environ Mol Mutagen. 2009;50(2):96-104.

37. Wang $\mathrm{H}$, Ye Y, Zhu M, Cho C. Increased interleukin- 8 expression by cigarette smoke extract in endothelial cells. Environ Toxicol Pharmacol. 2000;9(1-2):19-23.

38. Orosz Z, Csiszar A, Labinskyy N, et al. Cigarette smoke-induced proinflammatory alterations in the endothelial phenotype: role of NAD(P)H oxidase activation. Am J Physiol Heart Circ Physiol. 2007;292(1):H130-H139.

39. Rius C, Company C, Piqueras L, et al. Critical role of fractalkine (CX3CL1) in cigarette smoke-induced mononuclear cell adhesion to the arterial endothelium. Thorax. 2013;68(2):177-186

40. Meng M, Liao H, Zhang B, et al. Cigarette smoke extracts induce overexpression of the proto-oncogenic gene interleukin-13 receptor alpha2 through activation of the PKA-CREB signaling pathway to trigger malignant transformation of lung vascular endothelial cells and angiogenesis. Cell Signal. 2017;31:15-25.

41. Barbieri SS, Weksler BB. Tobacco smoke cooperates with interleukin1beta to alter beta-catenin trafficking in vascular endothelium resulting in increased permeability and induction of cyclooxygenase- 2 expression in vitro and in vivo. FASEB J. 2007;21(8):1831-1843.

42. Allam E, Delacruz K, Ghoneima A, Sun J, Windsor LJ. Effects of tobacco on cytokine expression from human endothelial cells. Oral Dis. 2013;19(7):660-665.

43. Ota Y, Kugiyama K, Sugiyama S, et al. Impairment of endotheliumdependent relaxation of rabbit aortas by cigarette smoke extract - role of free radicals and attenuation by captopril. Atherosclerosis 1997;131(2):195-202.

44. Kagota S, Yamaguchi Y, Shinozuka K, Kwon YM, Kunitomo M. Cigarette smoke-modified low density lipoprotein impairs endotheliumdependent relaxation in isolated rabbit arteries. Gen Pharmacol. 1996;27(3):477-481.

45. Snajdar RM, Busuttil SJ, Averbook A, Graham DJ. Inhibition of endothelial cell migration by cigarette smoke condensate. J Surg Res. 2001;96(1):10-16.

46. Bjornstad HH, Bruvik J, Bjornstad AB, Hjellestad BL, Damas JK, Aukrust P. Exercise training decreases plasma levels of soluble CD40 ligand and P-selectin in patients with chronic heart failure. Eur $J$ Cardiovasc Prev Rehabil. 2008;15(1):43-48.

47. de Sa FG, da Mota GR, Sant'Ana PG, da Cunha MR, Marocolo M, Castardeli E. Training and cardiovascular responses from cigarette smoke exposure. Chin J Physiol. 2014;57(6):315-319.

48. Tilton SC, Karin NJ, Webb-Robertson BJ, et al. Impaired transcriptional response of the murine heart to cigarette smoke in the setting of high fat diet and obesity. Chem Res Toxicol. 2013;26(7):1034-1042.

49. Stallones RA. The association between tobacco smoking and coronary heart disease. Int J Epidemiol. 2015;44(3):735-743.

50. Zhang J, Fang SC, Mittleman MA, Christiani DC, Cavallari JM. Secondhand tobacco smoke exposure and heart rate variability and inflammation among non-smoking construction workers: a repeated measures study. Environ Health. 2013;12(1):83.

51. Blackburn H. Environmental tobacco smoke exposure was associated with an increased risk of ischemic heart disease. Evid Based Cardiovasc Med. 1998;2(2):43-44.

52. Japuntich SJ, Eilers MA, Shenhav S, et al. Secondhand tobacco smoke exposure among hospitalized nonsmokers with coronary heart disease. JAMA Intern Med. 2015;175(1):133-136.

53. Vandivier RW. Learning to act on secondhand tobacco smoke exposure to limit risk for coronary heart disease. JAMA Intern Med. 2015;175(1):136.
54. Enstrom JE, Kabat GC. Environmental tobacco smoke and coronary heart disease mortality in the United States - a meta-analysis and critique. Inhal Toxicol. 2006;18(3):199-210.

55. Das A, Dey N, Ghosh A, Das S, Chattopadhyay DJ, Chatterjee IB. Molecular and cellular mechanisms of cigarette smoke-induced myocardial injury: prevention by vitamin C. PLoS One. 2012;7(9):e44151.

56. Leone A. Biochemical markers of cardiovascular damage from tobacco smoke. Curr Pharm Des. 2005;11(17):2199-2208.

57. Izzotti A, D’Agostini F, Balansky R, et al. Exposure of mice to cigarette smoke and/or light causes DNA alterations in heart and aorta. Mutat Res. 2008;644(1-2):38-42.

58. Zhou X, Li C, Xu W, Chen J. Trimetazidine protects against smokinginduced left ventricular remodeling via attenuating oxidative stress, apoptosis, and inflammation. PLoS One. 2012;7(7):e40424.

59. Zhou X, Li C, Xu W, Chen J. Protective effects of valsartan against cigarette smoke-induced left ventricular systolic dysfunction in rats. Int J Cardiol. 2013;167(3):677-680.

60. Khanna AK, Xu J, Mehra MR. Antioxidant N-acetyl cysteine reverses cigarette smoke-induced myocardial infarction by inhibiting inflammation and oxidative stress in a rat model. Lab Investig. 2012;92:224-235.

61. Halappanavar S, Stampfli MR, Berndt-Weis L, Williams A, Douglas GR, Yauk CL. Toxicogenomic analysis of mainstream tobacco smokeexposed mice reveals repression of plasminogen activator inhibitor-1 gene in heart. Inhal Toxicol. 2009;21(1):78-85.

62. McCall MR, van den Berg JJ, Kuypers FA, et al. Modification of LCAT activity and HDL structure. New links between cigarette smoke and coronary heart disease risk. Arterioscler Thromb. 1994;14(2):248-253.

63. Gea J, Agustí A, Roca J. Pathophysiology of muscle dysfunction in COPD. J Appl Physiol (1985). 2013;114(9):1222-1234.

64. Krüger K, Seimetz S, Ringseis R, et al. Exercise training reverses inflammation and muscle wasting after smoke exposure. Am J Physiol Regul Integr Comp Physiol. 2017 Epub Nov 1.

65. Basic VT, Tadele E, Elmabsout AA, et al. Exposure to cigarette smoke induces overexpression of von Hippel-Lindau tumor suppressor in mouse skeletal muscle. Am J Physiol Lung Cell Mol Physiol. 2012;303(6):L519-L527.

66. Gomes MD, Lecker SH, Jagoe RT, Navon A, Goldberg AL. Atrogin-1, a muscle531 specific F-box protein highly expressed during muscle atrophy. Proc Natl Acad Sci U S A. 2001;98(25):14440-14445.

67. Dutta P, Courties G, Wei Y, et al. Myocardial infarction accelerates atherosclerosis. Nature. 2012;487(7407):325-329.

68. Hafezi-Moghadam A, Thomas KL, Wagner DD. ApoE deficiency leads to a progressive age-dependent blood-brain barrier leakage. $\mathrm{Am}$ J Physiol Cell Physiol. 2007;292(4):C1256-C1262.

69. Manna SK, Rangasamy T, Wise K, et al. Long term environmental tobacco smoke activates nuclear transcription factor-kappa B, activator protein-1, and stress responsive kinases in mouse brain. Biochem Pharmacol. 2006;71(11):1602-1609.

70. Seo SB, Choe ES, Kim KS, Shim SM. The effect of tobacco smoke exposure on the generation of reactive oxygen species and cellular membrane damage using co-culture model of blood brain barrier with astrocytes. Toxicol Ind Health. 2017;33(6):530-536.

71. Prasad S, Sajja RK, Park JH, Naik P, Kaisar MA, Cucullo L. Impact of cigarette smoke extract and hyperglycemic conditions on blood-brain barrier endothelial cells. Fluids Barriers CNS. 2015;12:18.

72. Wang J, Dore S. Heme oxygenase-1 exacerbates early brain injury after intracerebral haemorrhage. Brain. 2007;130(Pt 6):1643-1652.

73. Ohno N, Tanaka T, Kita T, et al. Changes of brain endothelin levels and peripheral endothelin receptors by chronic cigarette smoke in spontaneously hypertensive rats. J Pharmacol Sci. 2004;94(3):287-296.

74. Paulson JR, Roder KE, McAfee G, Allen DD, Van der Schyf CJ, Abbruscato TJ. Tobacco smoke chemicals attenuate brain-to-blood potassium transport mediated by the $\mathrm{Na}, \mathrm{K}, 2 \mathrm{Cl}$-cotransporter during hypoxia-reoxygenation. J Pharmacol Exp Ther. 2006;316(1):248-254.

75. Fuller BF, Gold MS, Wang KK, Ottens AK. Effects of environmental tobacco smoke on adult rat brain biochemistry. J Mol Neurosci. 2010; 41(1):165-171. 
76. McCarthy B, Casey D, Devane D, Murphy K, Murphy E, Lacasse Y. Pulmonary rehabilitation for chronic obstructive pulmonary disease. Cochrane Database Syst Rev. 2015;2:CD003793.

77. Pedersen BK, Febbraio MA. Muscle as an endocrine organ: focus on muscle-derived interleukin-6. Physiol Rev. 2008;88(4):1379-1406.

78. Gleeson M, Bishop NC, Stensel DJ, Lindley MR, Mastana SS, Nimmo MA. The anti-inflammatory effects of exercise: mechanisms and implications for the prevention and treatment of disease. Nat Rev Immunol. 2011;11(9):607-615.

79. Pedersen BK. Anti-inflammatory effects of exercise: role in diabetes and cardiovascular disease. Eur J Clin Invest. 2017;47(8):600-611.

80. Maynard CL, Weaver CT. Diversity in the contribution of IL 10 to cell-mediated immune regulation. Immunol Rev. 2008;226:219-233.

81. Moore KW, de Waal Malefyt R, Coffman RL, O'Garra A. Interleukin 10 and the interleukin 10 receptor. Аnпи Rev Immunol. 2001;19:683-765.

82. Bergmann M, Gornikiewicz A, Sautner T, et al. Attenuation of catecholamine-induced immunosuppression in whole blood from patients with sepsis. Shock. 1999;12(6):421-427.

83. Gleeson M, McFarlin BK, Flynn MG. Exercise and Toll-like receptors. Exerc Immunol Rev. 2006;12:34-53.

84. Oliveira M, Gleeson M. The influence of prolonged cycling on monocyte Toll-like receptor 2 and 4 expression in healthy men. Eur J Appl Physiol. 2010;109(2):251-257.

85. Skinner NA, MacIsaac CM, Hamilton JA, VisvanathanK. Regulation of Toll-like receptor (TLR)2 and TLR4 on CD14dimCD16+ monocytes in response to sepsis-related antigens. Clin Exp Immunol. 2005;141(2):270-278.

86. Timmerman KL, Flynn MG, Coen PM, Markofski MM, Pence PB. Exercise training-induced lowering of inflammatory (CD14+CD16+) monocytes: a role in the anti-inflammatory influence of exercise? Leukoc Biol. 2008;84(5):1271-1278.

87. Shaw DM, Merien F, Braakhuis A, Dulson D. T-cells and their cytokine production: the anti-inflammatory and immunosuppressive effects of strenuous exercise. Cytokine. 2017; pii:S1043-4666(17)30292-2.

88. Weinhold M, Shimabukuro-Vornhagen A, Franke A, et al. Physical exercise modulates the homeostasis of human regulatory $\mathrm{T}$ cells. J Allergy Clin Immunol. 2016;137(5):1607-1610.e8.

89. Krüger K. Inflammation during obesity - pathophysiological concepts and effects of physical activity. Dtsch Z Sportmed. 2017;68: 163-169.

90. Oliveira AG, Araujo TG, Carvalho BM, Guadagnini D, Rocha GZ, Bagarolli RA. Acute exercise induces a phenotypic switch in adipose tissue macrophage polarization in diet-induced obese rats. Obesity. 2013;21:2545-2556

91. Kawanishi N, Yano H, Yokogawa Y, Suzuki K. Exercise training inhibits inflammation in adipose tissue via both suppression of macrophage infiltration and acceleration of phenotypic switching from M1 to M2 macrophages in high-fat-diet-induced obese mice. Exerc Immunol Rev. 2010;16:105-118.

92. Lowder T, Dugger K, Deshane J, Estell K, Schwiebert LM. Repeated bouts of aerobic exercise enhance regulatory $\mathrm{T}$ cell responses in a murine asthma model. Brain Behav Immun. 2010;24(1):153-159.

93. Pastva A, Estell K, Schoeb TR, Atkinson TP, Schwiebert LM. Aerobic exercise attenuates airway inflammatory responses in a mouse model of atopic asthma. J Immunol. 2004;172(7):4520-4526.

94. Dugger KJ, Chrisman T, Jones B, et al. Moderate aerobic exercise alters migration patterns of antigen specific $T$ helper cells within an asthmatic lung. Brain Behav Immun. 2013;34:67-78.

95. Lakier Smith L. Overtraining, excessive exercise, and altered immunity: is this a T helper-1 versus T helper-2 lymphocyte response? Sports Med. 2003;33(5):347-364.

96. Onur E, Kabaroğlu C, Günay O, et al. The beneficial effects of physical exercise on antioxidant status in asthmatic children. Allergol Iтmиnopathol (Madr). 2011;39(2):90-95.

97. Menegali BT, Nesi RT, Souza PS, et al. The effects of physical exercise on the cigarette smoke-induced pulmonary oxidative response. Pulm Pharmacol Ther. 2009;22(6):567-573.
98. Yu BU, Liao YW, Su KH, et al. Prior exercise training alleviates the lung inflammation induced by subsequent exposure to environmental cigarette smoke. Acta Physiol (Oxf). 2012;205(4):532-554.

99. Rennard SI, Drummond MB. Early chronic obstructive pulmonary disease: definition, assessment, and prevention. Lancet. 2015;385(9979): 1778-1788.

100. Saey D, Debigare R, LeBlanc P, et al. Contractile leg fatigue after cycle exercise: a factor limiting exercise in patients with chronic obstructive pulmonary disease. Am J Respir Crit Care Med. 2003;168(4):425-430.

101. Van Helvoort HA, Heijdra YF, Thijs HM, Vina J, Wanten GJ, Dekhuijzen PN. Exercise-induced systemic effects in muscle-wasted patients with COPD. Med Sci Sports Exerc. 2006;38(9):1543-1552.

102. Abd El-Kader SM, Al-Jiffri OH, Al-Shreef FM. Plasma inflammatory biomarkers response to aerobic versus resisted exercise training for chronic obstructive pulmonary disease patients. Afr Health Sci. 2016;16(2):507-515.

103. El-Sayed MS, Sale C, Jones PG, Chester M. Blood hemostasis in exercise and training. Med Sci Sports Exerc. 2000;32(5):918-925.

104. Clarkson P, Montgomery HE, Mullen MJ, et al. Exercise training enhances endothelial function in young men. $J \mathrm{Am}$ Coll Cardiol. 1999;33(5):1379-1385.

105. Kelly AS, Wetzsteon RJ, Kaiser DR, Steinberger J, Bank AJ, Dengel DR. Inflammation, insulin, and endothelial function in overweight children and adolescents: the role of exercise. J Pediatr. 2004;145(6):731-736.

106. Hambrecht R, Wolf A, Gielen S, et al. Effect of exercise on coronary endothelial function in patients with coronary artery disease. $N \mathrm{Engl}$ J Med. 2000;342(7):454-460.

107. Hambrecht R, Adams V, Erbs S, et al. Regular physical activity improves endothelial function in patients with coronary artery disease by increasing phosphorylation of endothelial nitric oxide synthase. Circulation. 2003;107(25):3152-3158.

108. Laufs U, Wassmann S, Czech T, et al. Physical inactivity increases oxidative stress, endothelial dysfunction, and atherosclerosis. Arterioscler Thromb Vasc Biol. 2005;25(4):809-814.

109. Morikawa Y, Mizuno Y, Harada E, et al. Aerobic interval exercise training in the afternoon reduces attacks of coronary spastic angina in conjunction with improvement in endothelial function, oxidative stress, and inflammation. Coron Artery Dis. 2013;24(3):177-182.

110. Babbitt DM, Diaz KM, Feairheller DL, et al. Endothelial activation microparticles and inflammation status improve with exercise training in African Americans. Int J Hypertens. 2013;2013:538017.

111. Zoppini G, Targher G, Zamboni C, et al. Effects of moderate-intensity exercise training on plasma biomarkers of inflammation and endothelial dysfunction in older patients with type 2 diabetes. Nutr Metab Cardiovasc Dis. 2006;16(8):543-549.

112. Wegge JK, Roberts CK, Ngo TH, Barnard RJ. Effect of diet and exercise intervention on inflammatory and adhesion molecules in postmenopausal women on hormone replacement therapy and at risk for coronary artery disease. Metabolism. 2004;53(3):377-381.

113. Adamopoulos S, Parissis J, Kroupis C, et al. Physical training reduces peripheral markers of inflammation in patients with chronic heart failure. Eur Heart J. 2001;22(9):791-797.

114. Walther C, Mobius-Winkler S, Linke A, et al. Regular exercise training compared with percutaneous intervention leads to a reduction of inflammatory markers and cardiovascular events in patients with coronary artery disease. Eur J Cardiovasc Prev Rehabil. 2008;15(1):107-112.

115. Nielsen HG, Lyberg T. Long-distance running modulates the expression of leucocyte and endothelial adhesion molecules. Scand J Immunol. 2004;60(4):356-362.

116. Bartzeliotou AI, Margeli AP, Tsironi M, et al. Circulating levels of adhesion molecules and markers of endothelial activation in acute inflammation induced by prolonged brisk exercise. Clin Biochem. 2007;40(11):765-770

117. Wisloff U, Stoylen A, Loennechen JP, et al. Superior cardiovascular effect of aerobic interval training versus moderate continuous training in heart failure patients: a randomized study. Circulation. 2007;115(24):3086-3094. 
118. Gibala MJ, Little JP, Macdonald MJ, Hawley JA. Physiological adaptations to low-volume, high-intensity interval training in health and disease. J Physiol. 2012;590(5):1077-1084.

119. Cugno M, Agostoni P, Mari D, et al. Impaired bradykinin response to ischaemia and exercise in patients with mild congestive heart failure during angiotensin-converting enzyme treatment. Relationships with endothelial function, coagulation and inflammation. $\mathrm{Br}$ J Haematol. 2005;130(1):113-120.

120. Jee H, Jin Y. Effects of prolonged endurance exercise on vascular endothelial and inflammation markers. JSports Sci Med.2012;11(4):719-726.

121. Nelson MR, Alkhateeb AN, Ryan P, et al. Physical activity, alcohol and tobacco use and associated cardiovascular morbidity and mortality in the Second Australian National Blood Pressure study cohort. Age Ageing. 2010;39(1):112-116.

122. Forstermann U, Mugge A, Alheid U, Haverich A, Frolich JC. Selective attenuation of endothelium-mediated vasodilation in atherosclerotic human coronary arteries. Circ Res. 1988;62(2):185-190.

123. Treasure CB, Vita JA, Cox DA, et al. Endothelium-dependent dilation of the coronary microvasculature is impaired in dilated cardiomyopathy. Circulation. 1990;81(3):772-779.

124. Mora S, Cook N, Buring JE, Ridker PM, Lee IM. Physical activity and reduced risk of cardiovascular events: potential mediating mechanisms. Circulation. 2007;116(19):2110-2118.

125. Garber CE, Blissmer B, Deschenes MR, et al. American College of Sports Medicine position stand. Quantity and quality of exercise for developing and maintaining cardiorespiratory, musculoskeletal, and neuromotor fitness in apparently healthy adults: guidance for prescribing exercise. Med Sci Sports Exerc. 2011;43(7):1334-1359.

126. O'Donovan G, Blazevich AJ, Boreham C, et al. The ABC of physical activity for health: a consensus statement from the British Association of Sport and Exercise Sciences. J Sports Sci. 2010;28(6): 573-591.

127. Guasch E, Benito B, Nattel S. Exercise training, inflammation and heart failure: working out to cool down. J Physiol. 2010;588(Pt 14): 2525-2526.

128. McMurray RG, Hicks LL, Thompson DL. The effects of passive inhalation of cigarette smoke on exercise performance. Eur J Appl Physiol Occup Physiol. 1985;54(2):196-200.

129. Ribeiro-Samora GA, Rabelo LA, Ferreira ACC, et al. Inflammation and oxidative stress in heart failure: effects of exercise intensity and duration. Braz J Med Biol Res. 2017;50(9):e6393.

130. Meyer P, Gayda M, Normandin E, Guiraud T, Juneau M, Nigam A. High-intensity interval training may reduce in-stent restenosis following percutaneous coronary intervention with stent implantation: a randomized controlled trial evaluating the relationship to endothelial function and inflammation. Am Heart J. 2009;158:734-741. Am Heart J. 2010;159(3):e21.
131. Terzis G, Stratakos G, Manta P, Georgiadis G. Throwing performance after resistance training and detraining. $J$ Strength Cond Res. 2008;22(4):1198-1204.

132. Walker DK, Dickinson JM, Timmerman KL, et al. Exercise, amino acids, and aging in the control of human muscle protein synthesis Med Sci Sports Exerc. 2011;43(12):2249-2258.

133. Zambom-Ferraresi F, Cebollero P, Gorostiaga EM, et al. Effects of combined resistance and endurance training versus resistance training alone on strength, exercise capacity, and quality of life in patients with COPD. J Cardiopulm Rehabil Prev. 2015;35(6):446-453.

134. Chirico EN, Di Cataldo V, Chauveau F, et al. Magnetic resonance imaging biomarkers of exercise-induced improvement of oxidative stress and inflammation in the brain of old high-fat-fed ApoE-/- mice. J Physiol. 2016;594(23):6969-6985.

135. Neeper SA, Gomez-Pinilla F, Choi J, Cotman C. Exercise and brain neurotrophins. Nature. 1995;373(6510):109.

136. Enos RT, Davis JM, McClellan JL, Murphy EA. Indomethacin in combination with exercise leads to muscle and brain inflammation in mice. J Interferon Cytokine Res. 2013;33(8):446-451.

137. Cotman CW, Berchtold NC, Christie LA. Exercise builds brain health: key roles of growth factor cascades and inflammation. Trends Neurosci. 2007;30(9):464-472.

138. Krüger K, Bredehoft J, Mooren FC, Rummel C. Different effects of strength and endurance exercise training on COX-2 and mPGES expression in mouse brain are independent of peripheral inflammation. J Appl Physiol (1985). 2016;121(1):248-254.

139. Burns JM, Swerdlow RH. Effect of high-intensity exercise on aged mouse brain mitochondria, neurogenesis, and inflammation. Neurobiol Aging. 2014;35(11):2574-2583.

140. Lu J, Selfridge JE, Burns JM, Swerdlow RH. Lactate administration reproduces specific brain and liver exercise-related changes. $J \mathrm{Neu}-$ rochem. 2013;127(1):91-100.

141. Mota BC, Pereira L, Souza MA, et al. Exercise pre-conditioning reduces brain inflammation and protects against toxicity induced by traumatic brain injury: behavioral and neurochemical approach. Neurotox Res. 2012;21(2):175-184.

142. Zoladz JA, Majerczak J, Zeligowska E, et al. Moderate-intensity interval training increases serum brain-derived neurotrophic factor level and decreases inflammation in Parkinson's disease patients. J Physiol Pharmacol. 2014;65(3):441-448.

143. Masson GS, Costa TS, Yshii L, et al. Time-dependent effects of training on cardiovascular control in spontaneously hypertensive rats: role for brain oxidative stress and inflammation and baroreflex sensitivity. PLoS One. 2014;9(5):e94927.

144. Tuon T, Valvassori SS, Lopes-Borges J, et al. Effects of moderate exercise on cigarette smoke exposure-induced hippocampal oxidative stress values and neurological behaviors in mice. Neurosci Lett. 2010;475(1):16-19.
Journal of Inflammation Research

\section{Publish your work in this journal}

The Journal of Inflammation Research is an international, peer-reviewed open access journal that welcomes laboratory and clinical findings on the molecular basis, cell biology and pharmacology of inflammation including original research, reviews, symposium reports, hypothesis formation and commentaries on: acute/chronic inflammation; mediators of inflammation; cellular processes; molecular mechanisms; pharmacology and novel anti-inflammatory drugs; clinical conditions involving inflammation. The manuscript management system is completely online and includes a very quick and fair peer-review system. Visit http://www.dove press.com/testimonials.php to read real quotes from published authors. 